\title{
Dexmedetomidine Ameliorates Sleep Deprivation-Induced Depressive Behaviors in Mice
}

\author{
Eun-Jin Moon ${ }^{1}$, Il-Gyu Ko², Sung-Eun Kim², Jun-Jang Jin², Lakkyong Hwang², Chang-Ju Kim², Hyeonjun An¹, Bong-Jae Lee ${ }^{1}$, \\ Jae-Woo $\mathrm{Yi}^{1}$ \\ ${ }^{1}$ Department of Anesthesiology and Pain Medicine, Kyung Hee University Hospital at Gangdong, College of Medicine, Kyung Hee University, Seoul, Korea \\ ${ }^{2}$ Department of Physiology, College of Medicine, Kyung Hee University, Seoul, Korea
}

\begin{abstract}
Purpose: Sleep deprivation induces depressive symptoms. Dexmedetomidine is a $\alpha_{2}$-adrenoreceptor agonist and this drug possesses sedative, anxiolytic, analgesic, and anesthetic-sparing effect. In this study, the action of dexmedetomidine on sleep deprivation-induced depressive behaviors was investigated using mice.

Methods: For the inducing of sleep deprivation, the mice were placed inside a water cage containing 15 platforms and filled with water up to $1 \mathrm{~cm}$ below the platform surface for 7 days. One day after sleep deprivation, dexmedetomidine at the respective dosage $(0.5,1$, and $2 \mu \mathrm{g} / \mathrm{kg})$ was intraperitoneally treated into the mice, one time per a day during 6 days. Then, forced swimming test and tail suspension test were conducted. Immunohistochemistry for tyrosine hydroxylase (TH), 5-hydroxytryptamine (5-HT; serotonin), tryptophan hydroxylase (TPH) and western blot for D1 dopamine receptor were also performed. Results: Sleep deprivation increased the immobility latency in the forced swimming test and tail suspension test. The expressions of TPH, 5-HT, and D1 dopamine receptor were decreased, whereas, TH expression was increased by sleep deprivation. Dexmedetomidine decreased the immobility latency and increased the expressions of TPH, 5-HT, and D1 dopamine receptor, whereas, HT expression was decreased by dexmedetomidine treatment.

Conclusions: In our results, dexmedetomidine alleviated sleep deprivation-induced depressive behaviors by increasing 5-HT synthesis and by decreasing dopamine production with up-regulation of D1 dopamine receptor.
\end{abstract}

Keywords: Sleep deprivation; Dexmedetomidine; Depression; Serotonin; Dopamine

- Fund/Grant Support: This work was supported by a grant from Kyung Hee University in 2015 (grant number: KHU-20151261).

- Research Ethics: All animal experimental procedures were approved by the Institutional Animal Care and Use Committee of Kyung Hee University (KHUASP [SE]-16-021), and performed in accordance with the National Institute of Health Council for the management and use of laboratory animals.

- Conflict of Interest: No potential conflict of interest relevant to this article was reported.

\section{- HIGHLIGHTS}

- Selective $\mathrm{a}_{2}$-adrenoreceptor agonist dexmedetomidine acts as an analgesic, sedative, and anesthetic-sparing agent.

- Dexmedetomidine alleviated sleep deprivation-induced depressive behaviors.

- The effect of dexmedetomidine was achieved by increasing serotonin synthesis and by decreasing dopamine production.

\section{INTRODUCTION}

Sleep deprivation is common in health care professionals and night shifts, and sleep deprivation causes anxiety, depressive symptoms, and impaired judgment [1]. Depressive symptoms are potent risk factor causing sleep disorders, and depression is
Corresponding author: Jae-Woo Yi (iD http://orcid.org/0000-0001-6474-5624 Department of Anesthesiology and Pain Medicine, Kangdong Kyung Hee Hospital, College of Medicine, Kyung Hee University, 892 Dongnam-ro, Gangdong-gu, Seoul 05278, Korea

E-mail: mdyjchk@khu.ac.kr / Tel: +82-2-440-6191 / Fax: +82-2-440-7808

Submitted: September 5, 2018 / Accepted after revision: October 10, 2018
This is an Open Access article distributed under the terms of the Creative Commons Attribution Non-Commercial License (http://creativecommons.org/licenses/by-nc/4.0/) which permits unrestricted non-commercial use, distribution, and reproduction in any medium, provided the original work is properly cited. 
also considered as one of the major complications in insomnia patients. Serotoninergic nervous system is associated with the modulation of sleep and wakefulness. Depression induces a functional decrease of central serotoninergic neurotransmission and depression is associated with the specific alterations of sleep, notably insomnia [2].

Serotonin (5-hydroxytryptamine, 5-HT) is implicated in many physiological functions, such as mood control, feeding, and sleep. Tryptophan hydroxylase (TPH) catalyzed 5-HT synthesis from tryptophan, which initially producing 5-hydroxytryptophan. Aromatic amino acid decarboxylase is involved in the decarboxylation of 5-hydroxytryptophan into 5-HT. Because TPH is known as the rate-limiting enzyme for the 5-HT production, the level of TPH has been used as an indicator for 5-HT synthesis. Dysfunction of 5-HT and its synthetic enzyme TPH is closely associated with depression or anxiety [3-5].

Dopamine neurons originate from the substantia nigra (SN) and project to the cerebral forebrain structures, such as prefrontal cortex (PFC) and striatum. In particular, striatum is a part of the anatomic network that aids in the function of dorsolateral PFC. Tyrosine hydroxylase (TH) catalyzes the production of L-dihydroxyphenylalanine, which is the rate-limiting step for the dopamine synthesis [6]. Functional loss of dopaminergic nervous control in humans causes diverse sleep disorders [7]. Pharmacologic drugs targeting to the dopaminergic neurotransmission are clinically used for the treatment of many neuropsychiatric diseases [8]. Acute sleep deprivation elevated TH expression in the ventral tegmental area, nucleus accumbens, and hypothalamus [9].

Dopamine receptors are one of the families included in the G-protein linked receptors. D1-like dopamine receptors (D1 dopamine receptor and $\mathrm{D} 5$ dopamine receptor) regulate cyclic AMP level positively [10]. D1 dopamine receptor is exclusively located at the postsynaptic site. On the other hand, D2-like dopamine receptors (D2 dopamine receptor, D3 dopamine receptor, and D4 dopamine receptor) are known to inhibit adenylate cyclase activity. D2 dopamine receptor and D3 dopamine receptor are presynaptically and postsynaptically present in both [11]. Dopamine receptors mediate all physiological actions by dopamine, from voluntary movement to hormonal regulation [8]. Of these, D1 dopamine receptor is associated with the action of antidepressants, and D1 dopamine receptor agonists have been considered as the potential antidepressants $[8,12]$.

Selective $\alpha_{2}$-adrenoreceptor agonist dexmedetomidine acts as an analgesic, sedative, and anesthetic-sparing agent [13].
Dexmedetomidine has been reported to exert neuroprotective effects against various brain insults through inhibiting neuronal apoptosis [14,15]. Dexmedetomidine induces sedation similar to natural sleep, and dexmedetomidine is a safe agent that does not induce apoptosis under the normal conditions $[16,17]$.

In this study, we investigated whether dexmedetomidine is effective on sleep deprivation-induced depression. For this experiment, forced swimming test, tail suspension test, immunohistochemcal staining for 5-HT, TPH, TH, and Western blot analysis for D1 dopamine receptor were conducted using mice.

\section{MATERIALS AND METHODS}

\section{Animal Treatments}

Male ICR mice, weighing $30 \pm 2 \mathrm{~g}$ (15 weeks in age), were purchased for this experiment. All animal experimental procedures were approved by the Institutional Animal Care and Use Committee of Kyung Hee University (KHUASP[SE]-16-021), and performed in accordance with the National Institute of Health Council for the management and use of laboratory animals.

The mice were bred at the controlled conditions $\left(23^{\circ} \mathrm{C} \pm 2^{\circ} \mathrm{C}\right.$ room temperature, 8:00 AM to 8:00 PM lighting). The animals were classified as the following five groups $(\mathrm{n}=10$ for each group): control, sleep deprivation, sleep deprivation and $0.5 \mu \mathrm{g} /$ $\mathrm{kg}$ dexmedetomidine-treated, sleep deprivation and $1 \mu \mathrm{g} / \mathrm{kg}$ dexmedetomidine-treated, and sleep deprivation and $2 \mu \mathrm{g} / \mathrm{kg}$ dexmedetomidine-treated groups. One day after sleep deprivation, dexmedetomidine at the respective dose $(0.5,1$, and $2 \mu \mathrm{g} /$ $\mathrm{kg}$ in $200 \mu \mathrm{L} \mathrm{NaCl}$ ) was intraperitoneally injected to the mice, one time per a day during 6 days.

\section{Induction of Sleep Deprivation}

Animal model of sleep deprivation was made using the method described previously $[18,19]$. Sleep deprivation was induced by placing the mice inside water cage $(90 \mathrm{~cm} \times 60 \mathrm{~cm} \times 40 \mathrm{~cm}$ high) containing 15 platforms ( $3 \mathrm{~cm}$ in diameter, $15 \mathrm{~cm}$ in height) and filled with water up to $1 \mathrm{~cm}$ beneath the platform surface, during 7 consecutive days. The mice were able to move or jump from one platform to the other inside of the water cage. Food and water were supplied into the grid placed on top of the water cage.

\section{Forced Swimming Test}

As the method described previously $[3,20]$, depression-like behavior was determined by the forced swimming test. Six days after sleep deprivation, a preliminary test was performed dur- 
ing 15 minutes. One day after a preliminary test, test was conducted for 5 minutes. Individually, the mice were located in a vertical plexiglass cylinder ( $40 \mathrm{~cm}$ height, 20 diameter) filled with $30 \mathrm{~cm}$ water at $25^{\circ} \mathrm{C} \pm 2^{\circ} \mathrm{C}$. For the forced swimming test, a Smart version 2.5 video tracking system (Panlab, Barcelona, Spain) calculated immobility. Immobility defines the limb and trunk as completely immobile. Following test, the mice were dried using a towel and placed in a separate cage, and were heated by a lamp until the mice were completely dry.

\section{Tail Suspension Test}

As the method described previously $[21,22]$, the tail suspension test is based on the action that the animal does not move if the animal gets stress that could not be avoided in a short period of time. Seven days after sleep deprivation, mouse was hung from a tube by its tail for 5 minutes approximately $10 \mathrm{~cm}$ away from the ground. During this time, the mouse tried to escape and reach to the ground. The time it takes until it remains immobile was measured.

\section{Tissue Preparation}

As the method described previously $[3,20]$, the mice were sacrificed immediately after tail suspension test. Zoletil $50(10 \mathrm{mg} /$ $\mathrm{kg}$; Vibac Laboratories, Carros, France) was used to anesthetize the mice, and then $50 \mathrm{mM}$ phosphate-buffered saline was transcardially perfused to the mice, and the mice were fixed by $4 \%$ paraformaldehyde in $100 \mathrm{mM}$ phosphate buffer $(\mathrm{pH}, 7.4)$. After that, the brains were removed, stored during overnight in the same fixation solution, and then treated with $30 \%$ sucrose for cryoprotection. Using a cryostat (Leica, Wetzlar, Germany), the slices were coronal sectioned with $40-\mu \mathrm{m}$ thickness. For the immunohistochemical staining, region spanning from Bregma 1.98 to $1.70 \mathrm{~mm}$ was selected for the PFC, region spanning from Bregma 0.74 to $0.38 \mathrm{~mm}$ was selected for the striatum, region spanning from Bregma -2.70 to $-3.28 \mathrm{~mm}$ was selected for the $\mathrm{SN}$, and region spanning from Bregma -4.36 to $-4.72 \mathrm{~mm}$ was selected for the dorsal raphe. The 10 average sections were selected from each mouse.

\section{Immunohistochemistry}

As the method described previously [20,23], we performed immunohistochemistry to detect the expression of 5-HT, TPH, and $\mathrm{TH}$. The tissue sections were treated with mouse anti-TH, mouse anti-TPH, and rabbit anti-5-HT antibody (1:1,000; Santa Cruz Biotechnology, Santa Cruz, CA, USA) during overnight.
The sections were treated with biotinylated anti-mouse $\mathrm{TH}$, anti-mouse TPH secondary antibody and with biotinylated antirabbit 5-HT secondary antibody (1:200; Vector Laboratories, Burlingame, CA, USA) during 1 hour. Next, avidin-biotin-peroxidase complex (Vector Laboratories) was treated to the section during 1 hour at $25^{\circ} \mathrm{C}$. The sections were treated with a reaction mixture consisting of $0.03 \%$ 3,3'-diaminobenzidine and $0.03 \%$ hydrogen peroxide during 5 minutes. After the slides were dried under the room conditions, Permount (Fisher Scientific, Fair Lawn, NJ, USA) was used for the coverslips mounting.

\section{Western Blotting}

As the method described previously [20,23], Western blotting was conducted to evaluated D1 dopamine receptor expression in the PFC, striatum, and SN. After dissecting PFC, striatum, and $\mathrm{SN}$, these tissues were collected. The tissues were treated with the lysis buffer composing $150 \mathrm{mM} \mathrm{NaCl}, 10 \%$ glycerol, $1 \%$ Triton X-100, $1 \mathrm{mM}$ phenylmethanesulfonyl fluoride, $1 \mathrm{mM}$ EGTA, $1.5 \mathrm{mM} \mathrm{MgCl}_{2} \cdot 6 \mathrm{H}_{2} \mathrm{O}, 1 \mathrm{mM}$ sodium orthovanadate, $100 \mathrm{mM}$ sodium fluoride, and 50mM HEPES (pH, 7.5). We used colorimetric protein assay kit (Bio-Rad, Hercules, CA, USA) to measure protein content in each sample. After separating protein samples $(30 \mu \mathrm{g})$ using sodium dodecyl sulfate-polyacrylamide gel, these samples were moved onto the nitrocellulose membrane. This membrane was treated with $5 \%$ skim milk in Tris-buffered saline with $0.1 \%$ Tween-20, and then the membrane was treated with following primary antibodies during overnight at $4^{\circ} \mathrm{C}$ : rabbit anti-GAPDH antibody and goat antiD1 dopamine receptor antibody (1:1,000; Santa Cruz Biotechnology). After that, the membrane was treated with secondary antibody (1:2,000; Vector Laboratories) during 1 hour. We used enhanced chemiluminescence detection kit (Santa Cruz Biotechnology) for the band detection.

\section{Data Analysis}

Densitometric analysis by an Image-Pro Plus image analysis system (Media Cybernetics Inc., Silver Spring, MD, USA) was conducted to confirm the expression of D1 dopamine receptor. Under the light microscope (Olympus, Tokyo, Japan), we counted the number of TH-positive cells in the $\mathrm{SN}$ and the number of TPH and 5-HT-positive cells in the dorsal raphe. By an image analyzer (Multiscan, Fullerton, CA, USA), we calculated the optical density of TH-immunoreactive fibers in the PFC and striatum at $100-\times 100-\mu \mathrm{m}$ area. Optical density of TH was corrected by the nonspecific background density, in which 
was completely denervated PFC and striatum. The formulation of optical density of TH-positive fibers in the PFC and striatum is as follows: optical density in the lesion side/optical density in the intact side.

One-way analysis of variance following by Duncan's posthoc test was used for the data analysis. Mean \pm standard error of the mean was presented for the results, and $\mathrm{P}<0.05$ was considered as significance.

\section{RESULTS}

\section{Immobility Latency in Forced Swimming Test and Tail Suspension Test}

Fig. 1 represents immobility latency of the forced swimming
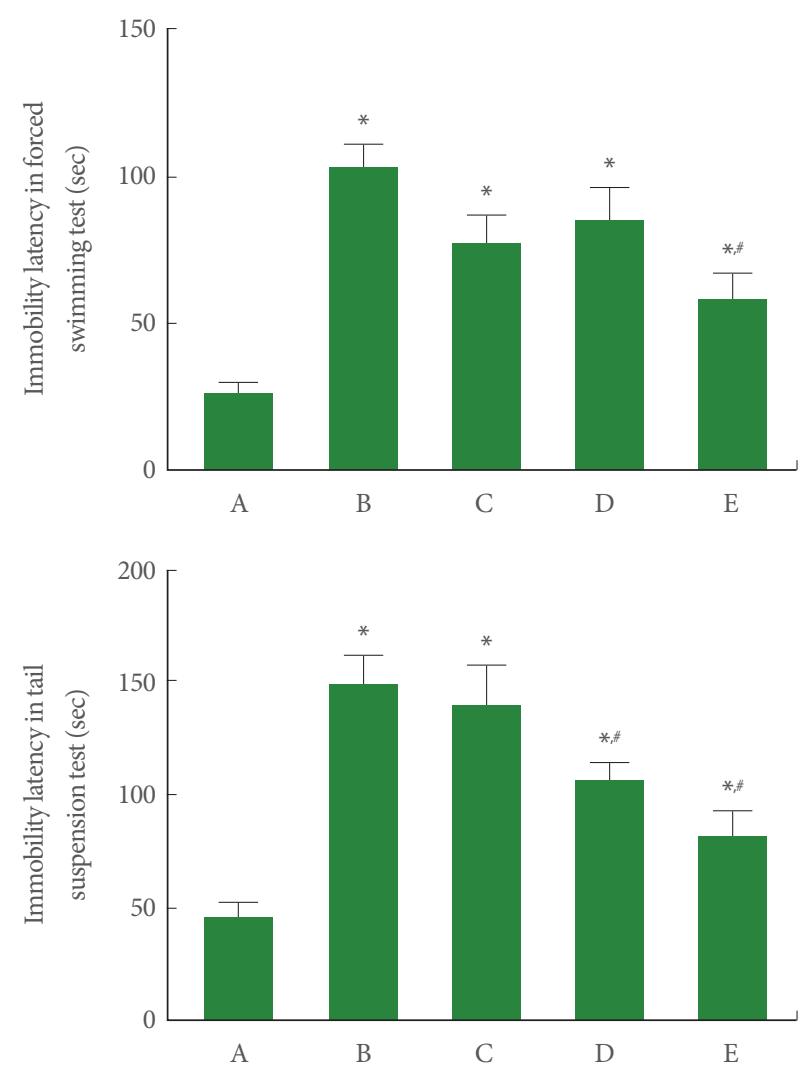

Fig. 1. Effect of dexmedetomidine on immobility latency in the forced swimming and tail suspension test. Upper panel: Immobility latency of forced swimming test. Lower panel: Immobility latency of tail suspension test. A, control group; B, sleep deprivation group; $\mathrm{C}$, sleep deprivation and $0.5 \mu \mathrm{g} / \mathrm{kg}$ dexmedetomidine-treated group; D, sleep deprivation and $1 \mu \mathrm{g} / \mathrm{kg}$ dexmedetomidine-treated group; E, sleep deprivation and $2 \mu \mathrm{g} / \mathrm{kg}$ dexmedetomidine-treated group. ${ }^{*} \mathrm{P}<0.05$ compared to the control group. ${ }^{*} \mathrm{P}<0.05$ compared to the sleep deprivation group. test and tail suspension test. In our results, immobility latency of the forced swimming test and tail suspension test was increased by sleep deprivation. Dexmedetomidine treatment shortened immobility latency in the forced swimming test $(\mathrm{F}=10.730, \mathrm{P}<0.001)$ and in the tail suspension test $(\mathrm{F}=12.490$, $\mathrm{P}<0.001)$ of the sleep deprived mice.

\section{TPH and 5-HT Expression in Dorsal Raphe}

Fig. 2 is photomicrographs of TPH-positive and 5-HT-positive cells in the dorsal raphe. In our results, sleep deprivation decreased TPH and 5-HT expression in the dorsal raphe. Dexmedetomidine treatment enhanced TPH $(\mathrm{F}=5.799, \mathrm{P}<0.01)$ and 5 -HT $(\mathrm{F}=11.861, \mathrm{P}<0.001)$ expression in the dorsal raphe of the sleep deprived mice.

\section{TH Expression in PFC, Striatum, and SN}

Fig. 3 is photomicrographs of TH expression in the PFC, striatum, and SN. In our results, sleep deprivation increased the $\mathrm{TH}$ expression in the PFC, striatum, and SN. Dexmedetomidine treatment suppressed $\mathrm{TH}$ expression in the PFC $(\mathrm{F}=12.490$, $\mathrm{P}<0.001)$, striatum $(\mathrm{F}=35.878, \mathrm{P}<0.001)$, and $\mathrm{SN}(\mathrm{F}=9.952$, $\mathrm{P}<0.001)$ of the sleep deprived mice.

D1 Dopamine Receptor Expression in PFC, striatum, and SN Fig. 4 is relative expression of D1 dopamine receptor in the PFC, striatum, and SN. In our results, sleep deprivation decreased the D1 dopamine receptor expression in the PFC, striatum, and SN. Dexmedetomidine treatment enhanced D1 dopamine receptor expression in the $\mathrm{PFC}(\mathrm{F}=8.253, \mathrm{P}<0.001)$, striatum $(\mathrm{F}=22.758, \mathrm{P}<0.001)$, and $\mathrm{SN}(\mathrm{F}=13.587, \mathrm{P}<0.001)$ of the sleep deprived mice.

\section{DISCUSSION}

One of the most widely known tests for determining antidepressant activity is the forced swimming test $[3,20]$. The forced swimming test is centered on a rodent's response to the threat of drowning (immobility behaviors), and the results are interpreted according to the measured susceptibility to negative mood. Likewise, the tail suspension test is an experimental method used to measure depressive behavior in rodents [21,22]. Sleep deprivation increased depressive behaviors such as immobility latency of the forced swimming test or tail suspension test in animals [24,25].

In our study, the immobility latency of both forced swim- 

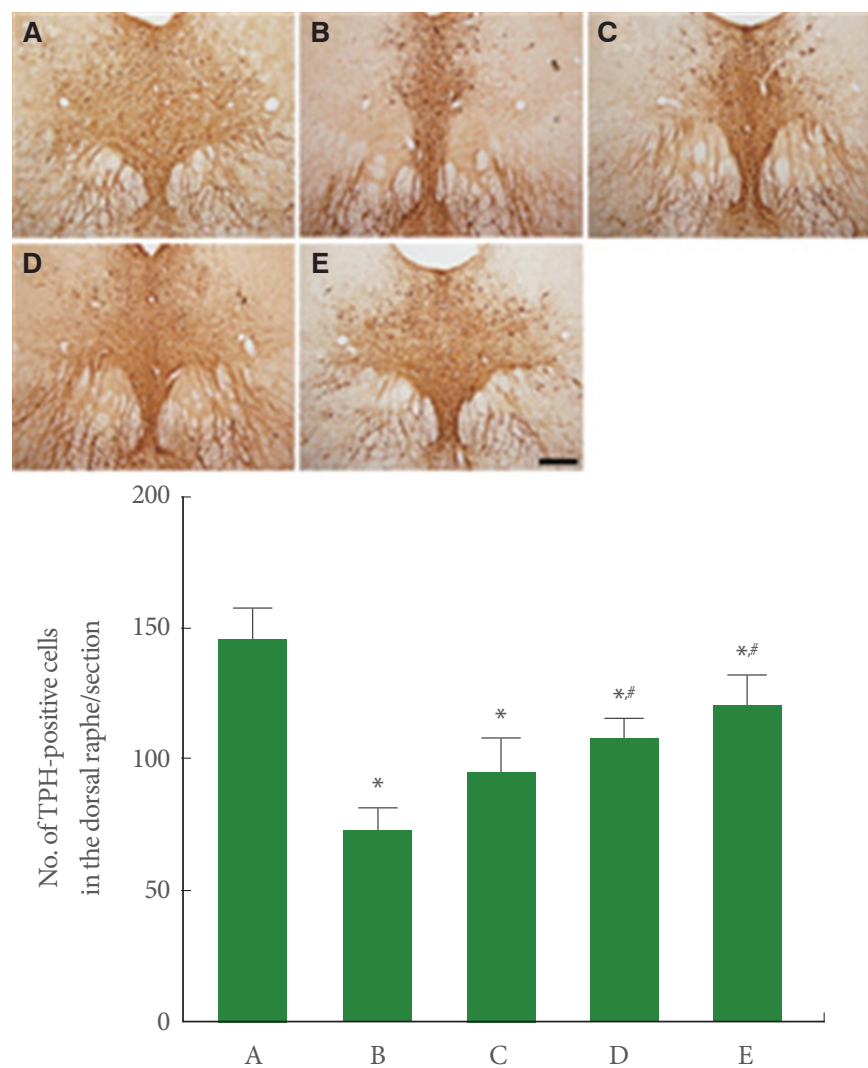
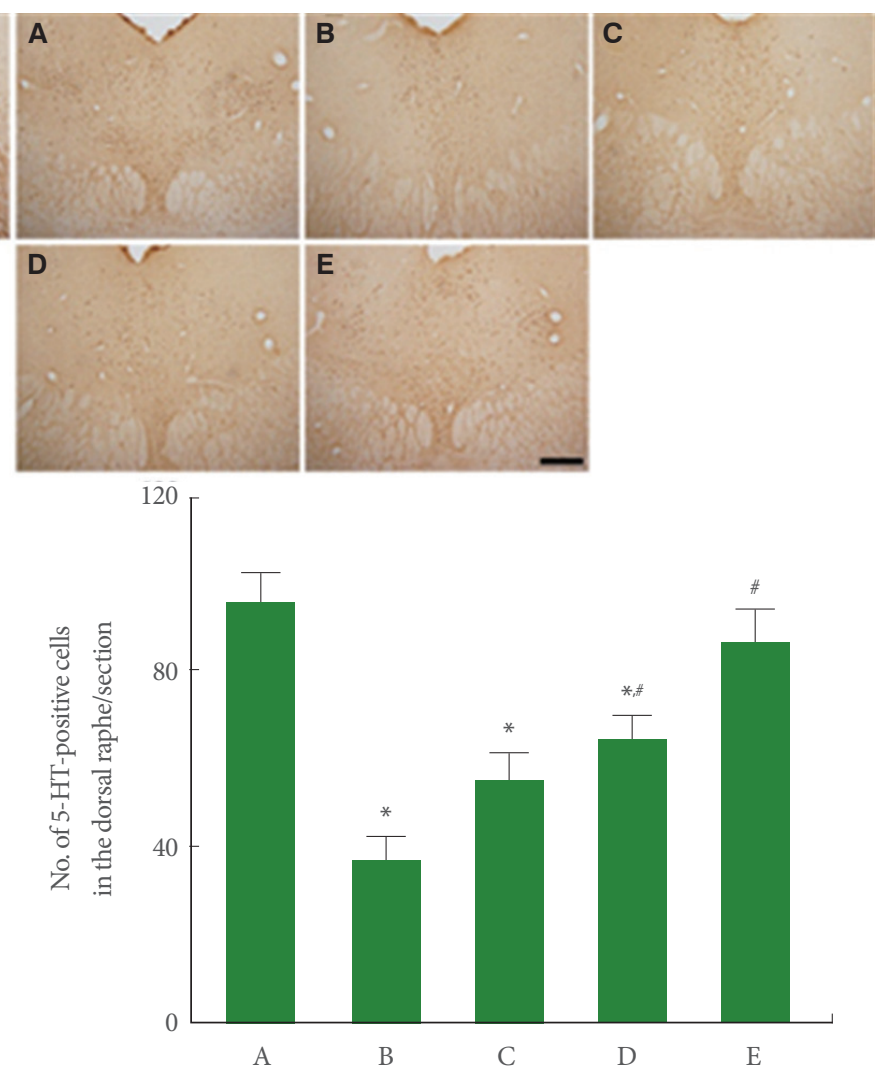

Fig. 2. Effect of dexmedetomidine on tryptophan hydroxylase (TPH) and 5-hydroxytryptamine (5-HT) expressions in the dorsal raphe. Upper panel: Photomicrographs of THP-positive cells (left) and 5-HT-positive cells (right) in the dorsal raphe. The scale bars represent $200 \mu \mathrm{m}$. Lower panel: Number of TPH-positive (left) and 5-HT-positive cells (right) in each group. A, control group; B, sleep deprivation group; $\mathrm{C}$, sleep deprivation and $0.5 \mu \mathrm{g} / \mathrm{kg}$ dexmedetomidine-treated group; $\mathrm{D}$, sleep deprivation and $1 \mu \mathrm{g} / \mathrm{kg}$ dexmedetomidine-treated group; E, sleep deprivation and $2 \mu \mathrm{g} / \mathrm{kg}$ dexmedetomidine-treated group. ${ }^{*} \mathrm{P}<0.05$ compared to the control group. ${ }^{*} \mathrm{P}<0.05$ compared to the sleep deprivation group.

ming test and tail suspension test was increased by sleep deprivation, indicating that sleep deprivation caused depressive behaviors in mice. Dexmedetomidine suppressed immobility latency of the forced swimming test and tail suspension test, suggesting that dexmedetomidine ameliorated sleep deprivationinduced depressive behaviors. Dexmedetomidine exerted antidepressant action via $\alpha_{2}$-adrenoreceptor in mice [26].

The development of rapid eye movement (REM) sleep is caused by a decrease of serotoninergic tone in the brain stem structure, thus antidepressants that increase serotoninergic tone inhibit REM sleep [2]. Sleep deprivation for 8 hours caused a gradual decline in extracellular fluid serotonin level in the hippocampus and prefrontal cortex [27]. Sleep restriction during one week evoked a blunted pituitary adrenocorticotropin response, and this blunted pituitary response might be associated with the decreased sensitivity to serotonin-1A receptor [18].
They concluded that chronic sleep deprivation could alter neurotransmitter receptor system and neuroendocrine responses similar to those seen in depression [18]. Repeated separation of their pups increased immobility latency in the forced swim test of the maternal rats, and 5-HT and TPH expressions in the dorsal raphe were declined in the depressive maternal rats [5]. Decreased levels of 5-HT and TPH expression were observed in the dorsal raphe of the depressive rat pups caused by maternal separation [3] and depressive rats with intracerebral hemorrhage [4].

In our study, the levels of 5-HT and TPH expression in the dorsal raphe were inhibited by sleep deprivation, indicating that suppression of 5-HT level in the dorsal raphe by sleep deprivation is closely related with depressive symptoms in mice. Dexmedetomidine enhanced 5-HT and TPH expression in the dorsal raphe, suggesting that dexmedetomidine restored sleep deprivation-induced decrease in 5-HT level. Enhanced 5-HT 

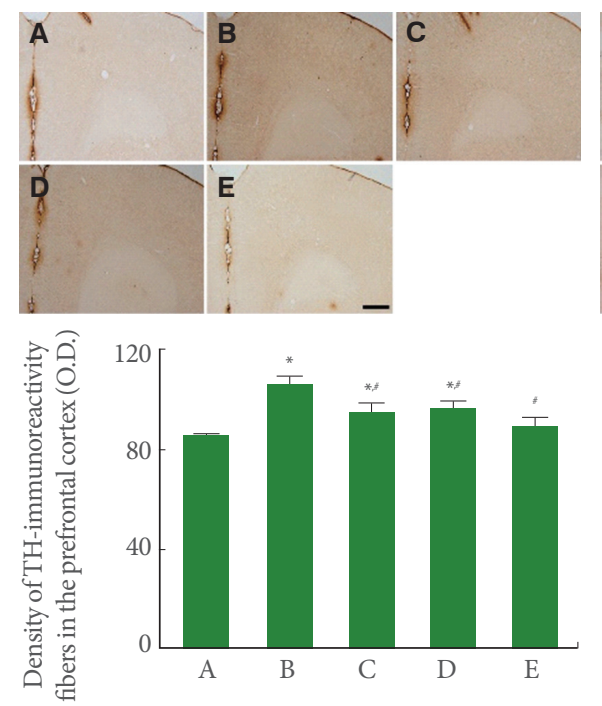
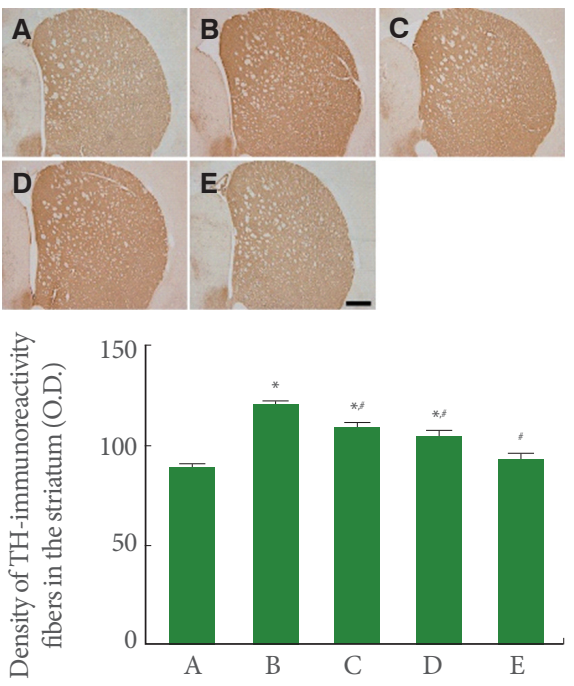
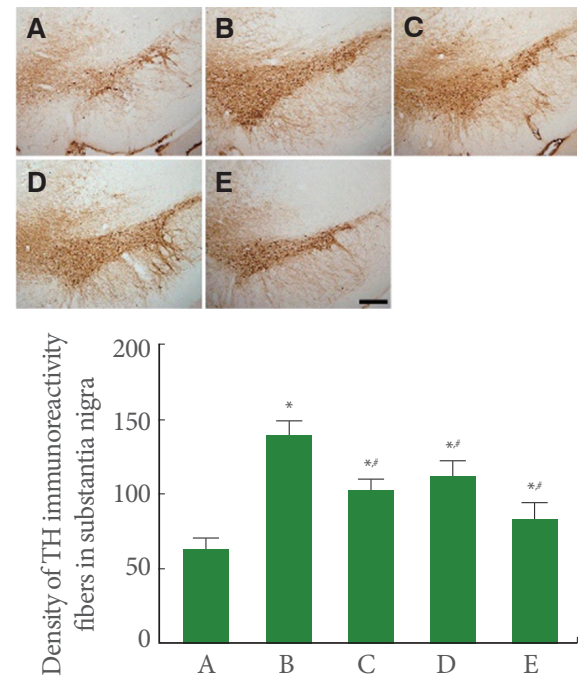

Fig. 3. Effect of dexmedetomidine on tyrosine hydroxylase (TH) expressions in the pre-frontal cortex (PFC), striatum, and substantia nigra (SN). Upper panel: Photomicrographs of TH-immunoreactivity fiber in the PFC (left), striatum (middle), and SN (right). The scale bars represent $200 \mu \mathrm{m}$. Lower panel: Density of TH immunoreactivity fiber in each group. A, control group; B, sleep deprivation group; $\mathrm{C}$, sleep deprivation and $0.5 \mu \mathrm{g} / \mathrm{kg}$ dexmedetomidine-treated group; $\mathrm{D}$, sleep deprivation and $1 \mu \mathrm{g} / \mathrm{kg}$ dexmedetomidine-treated group; E, sleep deprivation and $2 \mu \mathrm{g} / \mathrm{kg}$ dexmedetomidine-treated group. ${ }^{*} \mathrm{P}<0.05$ compared to the control group. ${ }^{~} \mathrm{P}<0.05$ compared to the sleep deprivation group.
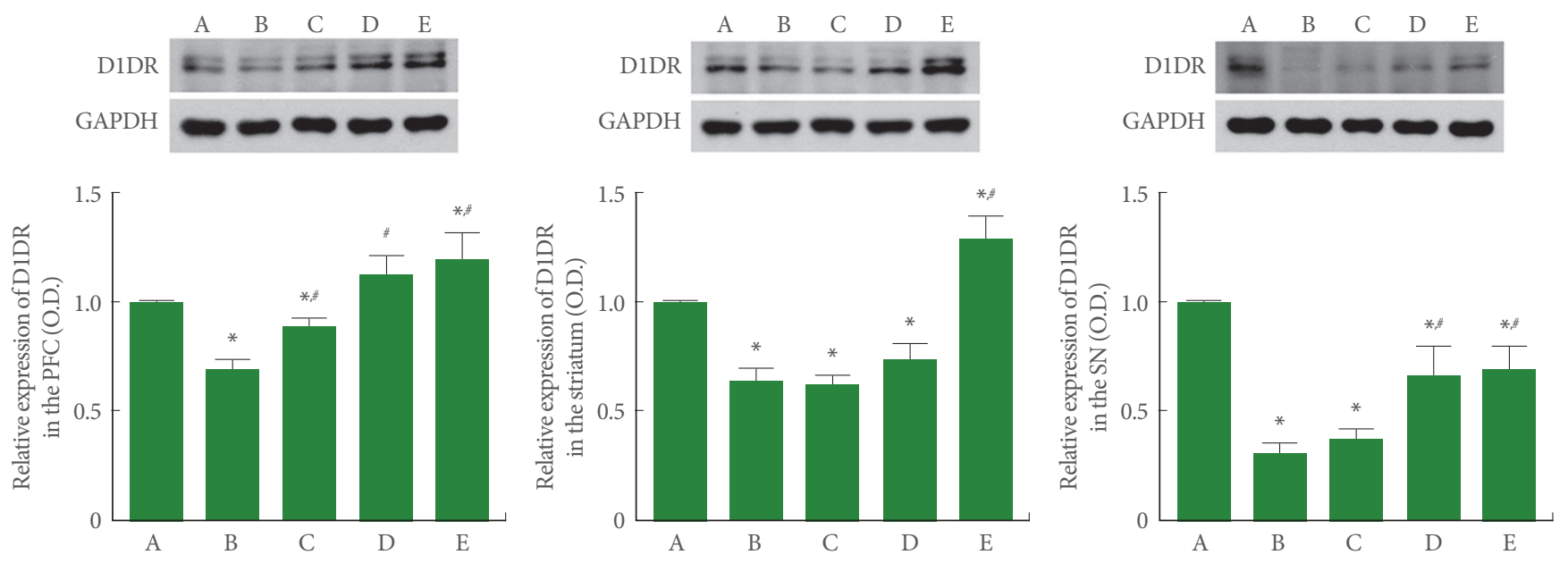

Fig. 4. Effect of dexmedetomidine on D1 dopamine receptor (D1DR) in the pre-frontal cortex (PFC), striatum, and substantia nigra (SN). Upper panel: The results of band detection using the enhanced chemiluminescence detection kit in PFC (left), striatum (middle), and SN (right). Lower panel: The relative expression of D1 dopamine receptor in each group. A, control group; B, sleep deprivation group; $\mathrm{C}$, sleep deprivation and $0.5 \mu \mathrm{g} / \mathrm{kg}$ dexmedetomidine-treated group; $\mathrm{D}$, sleep deprivation and $1 \mu \mathrm{g} / \mathrm{kg}$ dexmedetomidinetreated group; E, sleep deprivation and $2 \mu \mathrm{g} / \mathrm{kg}$ dexmedetomidine-treated group. ${ }^{*} \mathrm{P}<0.05$ compared to the control group. ${ }^{*} \mathrm{P}<0.05$ compared to the sleep deprivation group.

and TPH expression in the dorsal raphe suggests that depressive symptoms were ameliorated $[4,20]$.

Sleep deprivation potentiated TH level in the sex reply-associated dopaminergic pathways [28]. TH level in the ventral teg- mental area, nucleus accumbens, and hypothalamus was enhanced by sleep deprivation [9]. Mesolimbic dopaminergic system is closely related with the development of neuropsychiatric disorders, including adulthood depression [12]. Increased TH 
activity means enhanced dopamine synthesis, in contrast, decreased TH activity is associated with the injury of dopaminergic neurons and fibers $[23,29]$.

In our study, the expression of TH in the PFC, striatum, and $\mathrm{SN}$ was enhanced by sleep deprivation, indicating that sleep deprivation increased dopamine synthesis in mice. Dexmedetomidine suppressed expression of TH in the PFC, striatum, and $\mathrm{SN}$, suggesting that dexmedetomidine alleviated sleep deprivation-induced overproduction of dopamine. Dexmedetomidine is known to decrease extracellular dopamine level, and this decrement of dopamine by dexmedetomidine was mediated through nucleus accumbens [30].

Sleep deprivation was accompanied by decrease of D1 dopamine receptor immunoreactivity and increase of D2 dopamine receptor immunoreactivity in the caudate nucleus [31]. D1 dopamine receptor level was decreased, in contrast, D2 dopamine receptor level was not changed, and D3 dopamine receptor level was increased in the striatum of mice by sleep deprivation. They suggested that dopaminergic circuits in the brain could be remodeled by sleep deprivation [19]. Long-term awakening inhibits the acquisition of short-term memory in mammals, while D1 dopamine receptor is essential for the rescue of sleepdeprivation-induced learning impairments [32]. D1 dopamine receptor mediates the anti-depressant-like effect [12]. High density level of the D1 dopamine receptor is appeared in the striatum, nucleus accumbens, substantia nigra, olfactory bulb, amygdala, and frontal cortex [8].

In our study, sleep deprivation decreased D1 dopamine receptor expression in the PFC, striatum, and $\mathrm{SN}$, indicating that sleep deprivation down-regulated D1 dopamine receptor in mice. The down-regulating effect of sleep deprivation on D1 dopamine receptor might be ascribed to the overproduction of dopamine caused by sleep deprivation. Dexmedetomidine enhanced this D1 dopamine receptor expression.

Dexmedetomidine showed anti-apoptotic effect in various brain diseases without any adverse effects [14,15]. Direct injection of $40-\mu \mathrm{g} / \mathrm{kg}$ dexmedetomidine into the brachial plexus did not show apoptosis and degeneration [16]. In our study, dexmedetomidine alleviated sleep deprivation-induced depressive behaviors by increasing 5 -HT synthesis and by decreasing dopamine production with up-regulation of D1 dopamine receptor. Based on our study, dexmedetomidine can be considered as a safe drug for patients with depression due to insomnia.

\section{AUTHOR CONTRIBUTION STATEMENT}

- Full access to all the data in the study and takes responsibility for the integrity of the data and the accuracy of the data analysis: EJM, JWY

- Study concept and design: BJL, JWY

- Acquisition of data: IGK, SEK, JJJ, $L H$

- Analysis and interpretation of data: IGK, HA

- Drafting of the manuscript: EJM, IGK

- Critical revision of the manuscript for important intellectual content: BJL, JWY

- Statistical analysis: IGK, SEK

- Obtained funding: JWY

- Administrative, technical, or material support: JJJ, LH

-Study supervision: $C J K, J W Y$

\section{REFERENCES}

1. Veasey S, Rosen R, Barzansky B, Rosen I, Owens J. Sleep loss and fatigue in residency training: a reappraisal. JAMA 2002;288:111624.

2. Adrien J. Neurobiological bases for the relation between sleep and depression. Sleep Med Rev 2002;6:341-51.

3. Baek SS, Jun TW, Kim KJ, Shin MS, Kang SY, Kim CJ. Effects of postnatal treadmill exercise on apoptotic neuronal cell death and cell proliferation of maternal-separated rat pups. Brain Dev 2012; 34:45-56.

4. Roh JH, Ko IG, Kim SE, Lee JM, Ji ES, Kim JH, et al. Treadmill exercise ameliorates intracerebral hemorrhage-induced depression in rats. J Exerc Rehabil 2016;12:299-307.

5. Sung YH, Shin MS, Cho S, Baik HH, Jin BK, Chang HK, et al. Depression-like state in maternal rats induced by repeated separation of pups is accompanied by a decrease of cell proliferation and an increase of apoptosis in the hippocampus. Neurosci Lett 2010;5; 470:86-90.

6. Haavik J, Toska K. Tyrosine hydroxylase and Parkinson's disease. Mol Neurobiol 1998;16:285-309.

7. Rye DB. Parkinson's disease and RLS: the dopaminergic bridge. Sleep Med 2004;5:317-28.

8. Beaulieu JM, Gainetdinov RR. The physiology, signaling, and pharmacology of dopamine receptors. Pharmacol Rev 2011;63:182-217.

9. Azogu I, de la Tremblaye PB, Dunbar M, Lebreton M, LeMarec N, Plamondon H. Acute sleep deprivation enhances avoidance learning and spatial memory and induces delayed alterations in neurochemical expression of GR, TH, DRD1, pCREB and Ki67 in rats. 
Behav Brain Res 2015;279:177-90.

10. Vallone D, Picetti R, Borrelli E. Structure and function of dopamine receptors. Neurosci Biobehav Rev 2000;24:125-32.

11. Deransart C, Landwehrmeyer GB, Feuerstein TJ, Lucking CH. Upregulation of $\mathrm{D} 3$ dopaminergic receptor $\mathrm{mRNA}$ in the core of the nucleus accumbens accompanies the development of seizures in a genetic model of absence-epilepsy in the rat. Brain Res Mol Brain Res 2001;94:166-77.

12. Amiri S, Amini-Khoei H, Mohammadi-Asl A, Alijanpour S, HajMirzaian A, Rahimi-Balaei M, et al. Involvement of D1 and D2 dopamine receptors in the anti-depressant-like effects of selegiline in maternal separation model of mouse. Physiol Behav 2016;163:10714.

13. Panzer O, Moitra V, Sladen RN. Pharmacology of sedative-analgesic agents: dexmedetomidine, remifentanil, ketamine, volatile anesthetics, and the role of peripheral Mu antagonists. Anesthesiol Clin 2011;29:587-605.

14. Choi IY, Hwang L, Jin JJ, Ko IG, Kim SE, Shin MS, et al. Dexmedetomidine alleviates cerebral ischemia-induced short-term memory impairment by inhibiting the expression of apoptosis-related molecules in the hippocampus of gerbils. Exp Ther Med 2017;13: $107-16$.

15. Hwang L, Choi IY, Kim SE, Ko IG, Shin MS, Kim CJ, et al. Dexmedetomidine ameliorates intracerebral hemorrhage-induced memory impairment by inhibiting apoptosis and enhancing brain-derived neurotrophic factor expression in the rat hippocampus, Int J Mol Med 2013;31:1047-56.

16. Han JH, Kim DO, Yi JW, Park SW, Kang WJ, Chol YK, et al. Dexmedetomidine, a2-adrenoceptor agonist, does not induce apoptosis in the brachial plexus of rats. Anim Cells Syst 2014;18:407-15.

17. Park JH, Ko IG, Kim SE, Jin JJ, Hwang L, Kim CJ, et al. Dexmedetomidine oral mucosa patch for sedation suppresses apoptosis in hippocampus of normal rats. Int Neurourol J 2017;21(Suppl 1):S3947.

18. Novati A, Roman V, Cetin T, Hagewoud R, den Boer JA, Luiten PG, et al. Chronically restricted sleep leads to depression-like changes in neurotransmitter receptor sensitivity and neuroendocrine stress reactivity in rats. Sleep 2008;31:1579-85.

19. Lim MM, Xu J, Holtzman DM, Mach RH. Sleep deprivation differentially affects dopamine receptor subtypes in mouse striatum. Neuroreport 2011;22:489-93.

20. Ji ES, Lee JM, Kim TW, Kim YM, Kim YS, Kim K. Treadmill exercise ameliorates depressive symptoms through increasing serotonin expression in postpartum depression rats. J Exerc Rehabil 2017; 13:130-5.
21. Holmes A, Li Q, Koenig EA, Gold E, Stephenson D, Yang RJ, et al. Phenotypic assessment of galanin overexpressing and galanin receptor R1 knockout mice in the tail suspension test for depressionrelated behavior. Psychopharmacology (Berl) 2005;178:276-85.

22. Rosa PB, Ribeiro CM, Bettio LE, Colla A, Lieberknecht V, Moretti $\mathrm{M}$, et al. Folic acid prevents depressive-like behavior induced by chronic corticosterone treatment in mice. Pharmacol Biochem Behav 2014;127:1-6.

23. Ko IG, Kim SE, Kim TW, Ji ES, Shin MS, Kim CJ, et al. Swimming exercise alleviates the symptoms of attention-deficit hyperactivity disorder in spontaneous hypertensive rats. Mol Med Rep 2013;8: 393-400.

24. Daniele TM, de Bruin PF, Rios ER, de Bruin VM. Effects of exercise on depressive behavior and striatal levels of norepinephrine, serotonin and their metabolites in sleep-deprived mice. Behav Brain Res 2017;332:16-22.

25. de Oliveira RA, Cunha GM, Borges KD, de Bruin GS, dos SantosFilho EA, Viana GS, et al. The effect of venlafaxine on behaviour, body weight and striatal monoamine levels on sleep-deprived female rats. Pharmacol Biochem Behav 2004;79:499-506.

26. Stone EA, Lin Y, Sarfraz Y, Quartermain D. Antidepressant-like action of intracerebral 6-fluoronorepinephrine, a selective full a-adrenoceptor agonist. Int J Neuropsychopharmacol 2011;14:31931.

27. Bjorvatn B, Grønli J, Hamre F, Sørensen E, Fiske E, Bjørkum AA, et al. Effects of sleep deprivation on extracellular serotonin in hippocampus and frontal cortex of the rat. Neuroscience 2002;113:32330.

28. Damasceno F, Skinner GO, Cordeiro JF, Ferraz MR, Almeida OM. Sleep deprivation affects sexual behavior and tyrosine hydroxylase (TH) levels in sexually experienced male rats. Physiol Behav 2008;94:405-11.

29. Shin MS, Kim TW, Lee JM, Ji ES, Lim BV. Treadmill exercise alleviates nigrostriatal dopaminergic loss of neurons and fibers in rotenone-induced Parkinson rats. J Exerc Rehabil 2017;13:30-5.

30. Whittington RA, Virág L. Dexmedetomidine-induced decreases in accumbal dopamine in the rat are partly mediated via the locus coeruleus. Anesth Analg 2006;10:448-55.

31. Oganesyan GA, Aristakesyan EA, Romanova IV, Belova VA, Artamokhina IV. The dopaminergic nigrostriatal system in sleep deprivation in cats. Neurosci Behav Physiol 2008;38:785-92.

32. Seugnet L, Suzuki Y, Vine L, Gottschalk L, Shaw PJ. D1 receptor activation in the mushroom bodies rescues sleep-loss-induced learning impairments in Drosophila. Curr Biol 2008;18:1110-7. 